
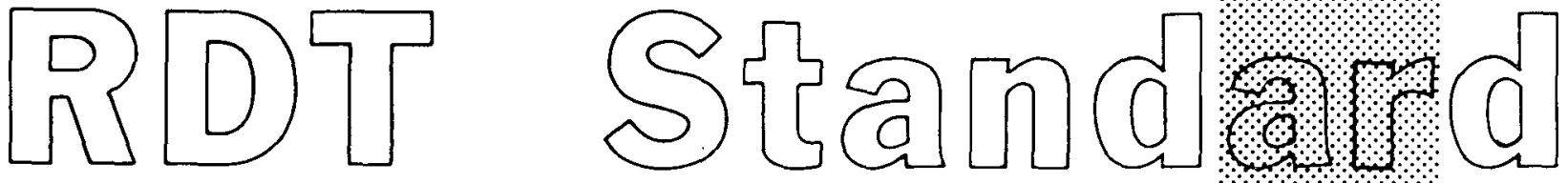

\title{
RUPTURE DISK DEVICES FOR LIQUID METAL SYSTEMS
}

\section{JULY 1973}

This report was prepared as an account of work sponsored by the United States Government. Neither the United States nor the United States Atomic Energy

Commission, nor any of their employees, nor any of their contractors, subcontractors, or their employees, their con makes any warranty, express or for the accuracy com plet liability or responsibiliy for the accuracy, coratus, pleteness or userulness of any informacion, apparatus, would not infringe privately owned rights.

Any further distribution by any holder of this document or of the data therein to third parties representing foreign interests, foreign governments, foreign companies, and foreign subsidiaries or foreign divisions of U.S. companies should be coordinated with the Director, Division of Reactor Research and Development, U.S. Atomic Energy Commission.

Division of Reactor Research and Development MIIIT United States Atomic Energy Commission 


\section{DISCLAIMER}

This report was prepared as an account of work sponsored by an agency of the United States Government. Neither the United States Government nor any agency Thereof, nor any of their employees, makes any warranty, express or implied, or assumes any legal liability or responsibility for the accuracy, completeness, or usefulness of any information, apparatus, product, or process disclosed, or represents that its use would not infringe privately owned rights. Reference herein to any specific commercial product, process, or service by trade name, trademark, manufacturer, or otherwise does not necessarily constitute or imply its endorsement, recommendation, or favoring by the United States Government or any agency thereof. The views and opinions of authors expressed herein do not necessarily state or reflect those of the United States Government or any agency thereof. 


\section{DISCLAIMER}

Portions of this document may be illegible in electronic image products. Images are produced from the best available original document. 
RDT STANDARD

UNITED STATES ATOMIC ENERGY COMMISSION

DIVISION OF REACTOR RESEARCH AND DEVELOPMENT
RDT E 1-11T

DATE July 1973

PAGE $i$

RUPTURE DISK DEVICES FOR LIQUID METAL SYSTEMS

TABLE OF CONTENTS

1. SCOPE

Page

1.1 Components and Services to be Provided 1

1.2 Definitions

2. APPLICABLE DOCUMENTS 1

2.1 RDT Standards 1

2.2 American National Standards Institute (ANSI) Standards 2

2.3 American Society of Mechanical Engineers (ASME)

2.4 Other Documents 2

2.5 Applicable Drawings 2

3. TECHNICAL REQUIREMENTS 2

3.1 General 2

3.2 Design and Performance Requirements 3

3.3 Operating Conditions 5

3.4 Design Analysis 6

3.5 Materials 6

3.6 Fabrication 7

3.7 Drawings 8

3.8 Technical Documentation and Reports 8

4. QUALITY ASSURANCE REQUIREMENTS 18

4.1 Quality Assurance Program 1

4.2 Quality Assurance Documents 9

4.3 Nondestructive Examination Requirements 9

4.4 Examination of Materials 9

4.5 Examination of Fabricated Items 10

4.6 Testing 10

5. PREPARATION FOR DELIVERY 11

6. NOTES AND ORDERING DATA CHECKLIST 11

6.1 Notes 11

6.2 Ordering Data Checklist 11 
RDT STANDARD

UNITED STATES ATOMIC ENERGY COMMISSION

DIVISION OF REACTOR RESEARCH AND DEVELOPMENT
RDT E 1-11T

DATE Ju1y 1973

PAGE 1 OF 13

RUPTURE DISK DEVICES FOR LIQUID METAL SYSTEMS

1. SCOPE

This standard delineates the requirements for rupture disk devices for installation in inert gas or liquid metal systems and related facilities for protection against overpressure or leakage. Rupture disk devices constructed in accordance with this standard will meet the requirements of the ASME

Boiler and Pressure Vessel Code, Sec. III (hereinafter referred to as the CODE), RDT E 15-2 and the additional requirements of this standard.

1.1 Components and Services to be Provided. Al1 components and services to be provided by the supplier shall be as specified in the Ordering Data.

1.2 Definitions. Rupture disk terminology utilized in this standard is in accordance with ANSI B95.1.

\section{APPLICABLE DOCUMENTS}

The following documents are a part of this standard to the extent specified herein. The issue of a document in effect on the date of invitation to bid, including any amendments also in effect on that date, shall apply unless otherwise specified. Where this standard appears to conflict with the requirements of a referenced document, such conflict shall be brought to the attention of the purchaser for resolution.

\subsection{RDT Standards.}

RDT E 15-2T Requirements for Nuclear Components (Supplement to ASME Boiler and Pressure Vesse1 Code, Section III)

RDT F 2-2T Quality Assurance Program Requirements

RDT F 2-4T Quality Verification Program Requirements

RDT F 4-20T Operation and Maintenance Manuals

RDT F 5-1T Cleaning and Cleanliness Requirements for Nuclear Components

RDT F 6-10T Repair of Materials by Welding

RDT F 7-2T Preparations for Sealing, Packaging, Packing, and Marking of Components for Shipment and Storage

RDT F 7-3T Requirements for Identification Marking of Reactor Plant Components and Piping 
RDT F 8-1T Preloading Threaded Fasteners and Closures

RDT F 8-6T Hoisting and Rigging of Critical Components and Related Equipment

RDT F 9-1T Requirements for Nuclear Components at Elevated Temperatures (Supplement to ASME Elevated Temperature Code Case 1331)

RDT M 6-2T Mechanical Locking Devices

\subsection{American National Standards Institute (ANSI) Standards.}

ANSI B1.1 Unified Screw Threads

ANSI B46.1 Surface Texture

ANSI B95.1 Terminology for Pressure Relief Devices

ANSI Y14 Drafting Manual

2.3 American Society of Mechanical Engineers (ASME).

ASME Boiler and Pressure Vessel Code

Section III, Nuclear Power Plant Components

Code Case 1331, Nuclear Components in High Temperature Service

2.4 Other Documents. (As specified in the Ordering Data)

2.5 Applicable Drawings. (As specified in the ordering Data)

3. TECHNICAL REQUIREMENTS

\subsection{General.}

3.1.1 Description. Rupture disk devices for liquid metal systems shall consist of a rupture disk mounted within a pressure-retaining component designed for installation in a piping system or a vessel by welding. The pressure-retaining boundaries shall be of all-welded construction for irradiated gas, sodium vapor or liquid sodium applications. Mechanical connections for other applications may be used with the approval of the purchaser. The rupture disk device may be equipped with such items as a vacuum support, fragmentation screen and excess flow valve.

Each rupture disk device, exclusive of the disk, shall meet the applicable requirements of the Code, RDT E 15-2, this standard and the supplemental requirements of the Ordering Data. For design temperatures above $800^{\circ} \mathrm{F}$, each rupture disk device shall meet the applicable requirements of ASME Code Case 1331 and RDT F 9-1. 
3.1.2 Function. Rupture disk devices for installation in piping systems will be used on the inlet side of pressure relief valves to prevent leakage of inert gas laden with sodium vapor and radioactive contaminants. Rupture disk devices for direct installation in vessels will be used for overpressure protection (such as steam generators) without the use of pressure relief valves.

3.1.3 Configuration. Any limitations on physical dimensions and the specific interface requirements such as dimensions of connecting piping or nozzles shall be as specified in the ordering Data.

\subsection{Design and Performance Requirements.}

3.2.1 Code Classification. The Code classification of the rupture disk device shall be as specified in the Ordering Data.

3.2.2 Design Pressure. The design pressure of the rupture disk device shall be as specified in the Ordering Data.

3.2.3 Design Temperature. The design temperature of the rupture disk device shall be as specified in the ordering Data.

3.2.4 Rupture Disk Burst Pressure. The burst pressure characteristics of each lot of rupture disks shall be established by testing samples at a test temperature specified in the Ordering Data. A lot of rupture disks is acceptable only when:

1. The average burst pressure is within the minimum and maximum values specified in the Ordering Data.

2. The rupture disks can be certified by the supplier to burst within the Code tolerance for bursting pressure based on the test requirements of 4.6 .1 or a more restrictive tolerance which may be specified in the ordering Data.

3.2.5 Relieving Capacity The relieving capacity of the rupture disk device shall equal or exceed the value specified in the Ordering Data. Unless otherwise specified in the ordering Data, verification of relieving capacity by test is required.

3.2.6 Leakage. The maximum allowable leakage rate for the rupture disk pressure-retaining boundary shall be $10^{-7} \mathrm{std} \mathrm{cc} / \mathrm{sec}$ as measured with a helium leak detector (mass spectrometer).

3.2.7 Design Mechanical Loads. The design mechanical loads for the rupture disk device will be specified in the Ordering Data.

3.2.8 Service Life. The design service life for the rupture disk device and the rupture disk shall be as specified in the ordering Data. 


\subsubsection{Provisions for Heaters and Insulation. Any requirements} for the provision of supports for attachment of heaters, insulation, or both by the purchaser will be specified in the Ordering Data.

3.2.10 Assurance of Correct Assembly. The design of the rupture disk device shall ensure that incorrect assembly cannot be achieved. The design of the disk and of the internal configuration of the device shall ensure that assembly in the inverted position cannot be physically accomplished. Auxiliary parts such as disk cutters or knives shall be designed to ensure assembly in the correct position and orientation. Both the approach and discharge channels of the rupture disk device shall be labelled and the flow direction for rupture indicated by stamping or other relief marking.

3.2.11 Assembly of Expendable Parts. Where a vacuum support, any type of retaining ring or protective cover, or both are used in conjunction with the rupture disk, the disk and such associated expendable parts shall be furnished as a preassembled, integral unit.

3.2.12 Vacuum Support. A vacuum support shall be supplied when required to protect the rupture disk from internal vacuum or high back pressure conditions. The maximum vacuum or back pressure condition will be specified in the ordering Data.

3.2.13 Retention of Disk Fragments. Means to contain fragments from a burst rupture disk within the rupture disk device shall be provided as specified in the Ordering Data. Where such provisions are specified, the design shall assure that the minimum relieving capacity requirements (3.2.5) are satisfied under any possible blockage conditions produced by entrapped fragments of the rupture disk or other expendable parts.

3.2.14 Seal Welding. All mechanical joints in the pressure-retaining boundary shall be seal welded.

\subsubsection{Bolting and Threaded Fastners.}

3.2.15.1 Screw Threads. Threaded elements shall conform to the following requirements.

1. Screw threads shall be in accordance with ANSI B1.1.

2. The Unified Thread Form shall be used.

3. Thread fits shall be Unified Class $2 \mathrm{~A}$ or $2 \mathrm{~B}$.

3.2.15.2 Locking Devices. Locking devices meeting the Class B requirements of RDT M 6-2 shall be provided for flange bolting.

3.2.15.3 Bolt Preload. The supplier shall establish the preload requirements for the flange bolting and provide installation instructions in accordance with $\mathrm{RDT} F$ 8-1. The temperatures at which installation may be required will be specified in the Ordering Data. 
3.2.16 Gaskets. Any gaskets required in the rupture disk device or for installation of the device shall be stainless steel spiral wound metal asbestos type or equivalent. Hydrocarbon or fluorocarbon gasket materials shall not be used.

\subsubsection{Provisions for Venting. Accessories for performing or} monitoring the venting function such as an excess flow valve or pressure gage shall be provided as required by the ordering Data.

3.2.18 Maintainability. All rupture disk devices weighing in excess of 50 pounds shall be provided with lifting eyes or other purchaser approved attachments for handling during installation or replacement.

3.2.19 Interchangeability. The rupture disk device shall be designed to assure the interchangeability of any or all parts with spare parts provided with the initial order or parts procured at a later date to the same design. All parts shall be marked to assure exact identification with the items as shown on the supplier's assembly drawing (3.7.2).

3.2.20 Surface Finish. Surfaces which will be examined by ultrasonic inspection shall have a roughness not to exceed 250 microinches (AA) as determined in accordance with ANSI B46.1.

3.2.21 Plating. Internal surfaces or parts of the rupture disk device shall not be plated.

3.2.22 Corrosion Allowance. Where required, the corrosion allowance or a basis for determining the corrosion allowance will be specified in the Ordering Data.

\subsection{Operating Conditions.}

3.3.1 System Operating Conditions. The operating conditions for the system in which the rupture disk devices will be installed are as follows:

1. Pressurizing Fluid - The pressurizing fluid in the system being protected and its normal and abnormal composition will be specified in the ordering Data.

2. Pressure - The normal system operating pressure and the number, rate and range of significant pressure transients will be specified in the Ordering Data.

3. Temperature - The normal approach channel temperature and the number, rate and range of significant temperature transients will be specified in the Ordering Data.

3.3.2 Environmental Conditions. The norma1 ambient conditions in which the rupture disk devices must operate and possible abnormal ambient conditions, including radiation levels and seismic loadings will be as specified in the Ordering Data. 
3.4 Design Analysis. A design analysis report shall be prepared by the supplier and shall include the following items:

1. Description of the rupture disk device and its appropriateness for the service conditions specified.

2. For Class 1 applications, a Stress Report prepared in accordance with the guidelines presented in Appendix $C$ of the Code.

3. Where required by the Ordering Data, an analysis of the methods used for assuring disk life under cyclic stress and temperature conditions.

The report shall be submitted to the purchaser for review by those responsible for the Design Specification before filing with the required authorities. Following certification that this review has been conducted, an appropriate insert page will be made available for inclusion by the supplier in the design report.

\subsection{Materials.}

3.5.1 General. A11 materials for parts within the boundaries of Code jurisdiction shall be in accordance with Code and the supplemental requirements of RDT E 15-2. Unless otherwise specified in the Ordering Data or approved by the purchaser, all parts that form part of the pressure-retaining boundary or are exposed to the contained fluid during normal operation shall be fabricated from 304 or 316 stainless steel or from nickel-iron-chromium alloys. Material specifications to be used shall be limited to those RDT standards listed in Tables NNB-2120-1 and NNB-2120-2 of RDT E 15-2. Optional requirements of the RDT standards that are to apply shall be as specified in the Ordering Data or as recommended by the supplier and approved by the purchaser.

3.5.2 Other Applications. Materials used for applications not within

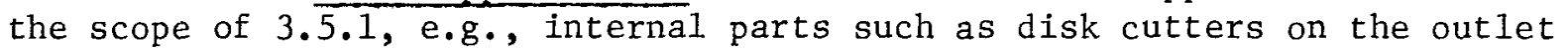
side of rupture disk, shall be as specified in the Ordering Data or as recommended by the supplier and approved by the purchaser. Unless otherwise specified in the Ordering Data or approved by the purchaser, nonmetallic materials shall not be used.

3.5.3 Archive Samples. Where required by the Ordering Data, samples of material used in fabrication shall be accumulated, identified and preserved for use as test reference specimens. The samples shall have the same metallurgical and environmental history as the parent materials in the rupture disk device. A plan for selection and test of materials shall be submitted to the purchaser. The required quantity of sample material will be specified in the Ordering Data. 


\subsection{Fabrication.}

3.6.1 General. Fabrication of rupture disk devices shall be in accordance with the Code and the supplemental requirements of RDT E 15-2. Fabrication of any item shall not be initiated without prior purchaser approval.

3.6.2 Joining and Cutting. All welding, brazing, hard surfacing, and thermal cutting shall be in accordance with the Code as supplemented by RDT E 15-2.

3.6.2.1 Material Repair. Welding processes for repair of defects in material may be used where permitted by the Code and the applicable material standard. Any such repair welding shall be performed in accordance with the requirements of RDT F 6-10. No repair welding of bolting or rupture disk material shall be permitted.

3.6.3 Heat Treatment. All heat treatment shall be in accordance with the applicable material standard.

3.6.3.1 Sensitization. Unless otherwise approved by the purchaser, austenitic stainless steel which has become sensitized during heat treatment, welding or forming shall be solution annealed per the applicable standard.

3.6.4 Cleaning. The fabrication of a part, combination of parts, subassembly, or completed assembly shall be conducted to facilitate cleaning and inspection for cleanliness, and to minimize contamination. Shop practices and restrictions on the use of materials shall be in accordance with RDT F 5-1. The supplier shall prepare for purchaser approval a cleaning procedure in accordance with RDT F 5-1 and include appropriate instructions and restrictions in his fabrication procedures and other documents defining acceptable shop practices.

Surfaces shall be maintained in a clean condition in accordance with RDT F 5-1 up to and including all assembly procedures.

Rupture disk devices cleaned in accordance with RDT F 5-1 will be suitable for installation into nuclear systems without additional cleaning.

\subsubsection{Marking.}

1. Raw materials shall be marked in accordance with the applicable RDT material standard.

2. Identification marking of all in-process parts and the permanent identification marking of parts shall be in accordance with the requirements of RDT F 7-3.

3. Rupture disk data required by the Code shall be marked on the exterior of the rupture disk device. 
3.6.6 Handling. Hoisting and rigging of parts and assembled rupture disk devices that are designated as "critical" in the Ordering Data shall satisfy the requirements of RDT F 8-6.

3.7 Drawings. Drawings shall be prepared in accordance with ANSI Y14. Detail and assembly drawings shall be submitted for purchaser approval prior to fabrication (3.6.1).

3.7.1 Detail Drawings. Detail drawings shall define all features of each part shown including, as applicable, configuration, dimensions, weights, center of gravity, tolerances, materials, mandatory processes, required nondestructive examinations, surface finish, markings, etc. All documents required to supplement the drawing through definition of material, fabrication, inspection and test requirements shall be referenced thereon.

3.7.2 Assembly Drawings. Assembly drawings shall define the assembled relationship of all parts of the rupture disk device and specify installation requirements either directly or by reference. The location of the supplier's coded design identification that is required for the rupture disk, shall be shown on the drawing. Serial numbers or other coded design identification to be marked on other parts of device shall be shown (3.2.19 and 3.6.5).

3.8 Technical Documentation and Reports. The supplier shall prepare the following documents and any additional documents specified in the ordering Data. The time of submittals and approval requirements shall be as specified in the Ordering Data.

3.8.1 Design Analysis Report. A design analysis report for Class 1 rupture disk devices shall be prepared in accordance with 3.4 .

3.8.2 Operations and Maintenance Manual. The supplier shall provide an Operations and Maintenance Manual in accordance with those requirements of RDT F 4-20 that are specified in the Ordering Data. This manual shall reflect the as-built configuration of the delivered item. Information shall include, but not be limited to, the following:

1. A detailed description of the rupture disk device and instructions for installation, operation, preventive maintenance and repair.

2. Reduced size drawings for operation, maintenance, and instructional purposes, including drawings of special tools and equipment.

\section{QUALITY ASSURANCE REQUIREMENTS}

4.1 Quality Assurance Program. Rupture disk devices that are essentially identical with an existing design and that have been proven successful by actual service experience under conditions equal to or more severe than those required by this standard shall be manufactured in accordance with a 
quality assurance program that meets the requirements of the Code and RDT F 2-4. Rupture disk devices not qualified by previous service experience shall be manufactured in accordance with the requirements of the Code and Sections 1 through 5, and 8 of RDT F 2-2.

The witness points will be specified by the purchaser on the quality verification plan of RDT F 2-4 or on the inspection and test plan of RDT F 2-2. The manufacturer shall notify the purchaser at least five days in advance of each witness point and shall confirm the schedule for each within 24 hours of the examination or test.

4.2 Quality Assurance Documents. The supplier shall prepare all applicable documentation required by the program requirements of 4.1 . The following documents and any additional documents specified in the Ordering Data shall be submitted to the purchaser. Time of submittal and approval requirements shall be as specified in the Ordering Data.

1. Quality Verification Plan or Inspection and Test Plan.

2. Sampling Plan - Determination of disk bursting pressure.

3. Nonconformance Records - A copy of each nonconformance and corrective action record.

4. Material Certifications - Including chemical and mechanical test results, nondestructive examination results, and heat treatment data. This data shall be traceable to the related finished parts.

5. Test Reports - Including test data, and any calculated test results for specified acceptance tests.

6. Inspection Results - Inspection data for a11 acceptance inspections identified in the Quality Verification Plan or Inspection and Test Plan.

4.3 Nondestructive Examination Requirements. Nondestructive examination of materials and fabricated components shall be performed in accordance with the Code as supplemented by RDT E 15-2.

The acceptance criteria sha1l be in accordance with the Code as supplemented by RDT E 15-2.

\subsection{Examination of Materials. Examination of materials prior to use} sha11 include: 
1. Examination for identification traceable to the material certifications. Non-traceable material is unacceptable.

2. Visual examination for conformance to cleanliness requirements.

3. Nondestructive examinations required by the materials specifications that have not been performed by the material supplier (3.5.1).

4.4.1 Repaired Material. Areas in material where defects have been removed and repair welding is not required shall be examined as required by the Code and RDT E 15-2. Areas repaired by welding sha11 be examined in accordance with RDT F 6-10. All weld repaired areas shall be examined by the methods and to the acceptance criteria required for the original examination.

4.5 Examination of Fabricated Items. All finished items shall be visually examined and measured to verify conformance to approved drawings.

4.5.1 Weld Examination. Visual, dimensional, and nondestructive examination of welds and repaired welds shall be in accordance with Code and RDT E 15-2.

4.5.2 Cleanliness. Items shall be examined for conformance to the cleanliness requirements of RDT F 5-1 (3.6.4).

4.5.3 Permanent Identifications. All finished parts shall be examined for compliance to the marking requirements of 3.6 .5 .

\subsection{Testing.}

4.6.1 Disk Burst Pressure. Unless otherwise specified in the Ordering Data, the supplier shall recommend the sampling plan for determination of burst pressure characteristics for the purchaser's approval. Where the plan is based on established variability of similar disks, the supplier shall provide such test data as required to justify use of the plan as a basis of the Code-required certification. The number of disks to be tested shall establish the basis for the Code-related certification of burst pressure tolerance and conformance to the performance requirements of 3.2.4. The supplier's test procedure shall be submitted to the purchaser for approval. Results of all individual determinations of burst pressure shall be reported.

Where the rupture disk devices are of all welded construction, a mechanically assembled test device may be used for disk testing providing the disk mounting configuration and conditions are typical of the devices being supplied.

4.6.2 Disk Life. Where specified in the Ordering Data or when recommended by the supplier and approved by the purchaser, endurance tests to establish the capability of disks to operate under the normal operating conditions (3.3.1) shall be performed to substantiate the calculated disk life 
(3.4). The supplier shall recommend test procedures for the purchaser's approval where such tests are to be performed.

4.6.3 Relieving Capacity. The minimum opening provided by the burst action of the disks tested in accordance with 4.6 .1 shall be observed and measurements made as required to verify that assumptions made in calculating relieving capacity are valid $(3.4)$.

4.6.4 Leak Testing. Leak testing of the rupture disk device shall be as specified in the Ordering Data. The leakage rate shall not exceed the leakage rate specified in 3.2.6. The supplier shall recommend a test procedure for the purchaser's approval.

\section{PREPARATION FOR DELIVERY}

Rupture disks and rupture disk devices shall be packaged, crated, and mounted to prevent deterioration, contamination or physical damage during transit to or storage at the installation site. Sealing, packaging, packing and marking shall be in accordance with RDT F 7-2.

As a minimum, each device shall be individually sealed in a polyethylene bag and boxed or crated for shipping. Spare parts and tools shall be individually packaged in moisture-vapor proof envelopes or polyethylene bags.

\section{NOTES AND ORDERING DATA CHECKLIST}

\subsection{Notes.}

6.1.1 Compliance. A registered professional engineer representing the purchaser will certify the purchase specification containing this standard and the Ordering Data for the rupture disk device to be correct, complete and in compliance with the Design Specification requirements of NA-3250 of the Code.

6.2 Ordering Data Checklist. Specific requirements and conditions for the design, fabrication, inspection, testing and delivery of the rupture disk device in accordance with this standard should be included in the ordering Data as shown in the following checklist:

The Ordering Data should be headed by the following statement:

The complete specification for Rupture Disk Devices for Liquid Metal Systems consists of RDT standard E 1-11, (date) and any amendments, modifications (if any) (date) and these Ordering Data. The applicable paragraph number of the standard is used herein to identify information that is required by the standard and any additional information included to define a requirement for this procurement. Any omission of paragraph numbers indicates that the particular paragraphs of the standard adequately specify the requirement.

\section{Scope.}

1.1 Summary of items and services to be provided. 


\section{App1icab1e Documents.}

2.1 - 2.5 Define issues of standards, amendments, codes and addenda in effect for this procurement.

List any supplemental codes, standards, drawings, or other documents which are referred to in the Ordering Data, but not listed in the standard.

\section{Technical Requirements.}

3.1.3 Specify any supplemental requirements including envelope and interface details.

3.2.1 Specify Code classification.

3.2.2 Specify design pressure.

3.2.3 Specify design temperature.

3.2.4 Specify minimum and maximum burst pressure and test temperature.

3.2.5 Specify minimum relieving capacity.

3.2.7 Specify design mechanical loads.

3.2.8 Specify service life requirements.

3.2.9 Specify heater and insulation supports.

3.2.12 Specify maximum vacuum or back pressure conditions.

3.2.13 Specify requirements for fragmentation screens or other devices.

3.2.15.3 Specify installation temperature requirements for bolting.

3.2.17 Specify accessories to be provided for drain or venting function.

3.3.1 (1) Specify system fluid normal and abnormal composition.

(2) Specify normal operating pressure, number and range of significant pressure transients.

(3) Specify normal operating temperature, rate and range of temperature transients.

3.3.2 Specify normal and abnormal environmental conditions. 
3.4 When required, specify submittal of design methods used assuring disk life.

3.5.1 Specify optional RDT standards requirements, if applicable. 3.5.3 Specify archive samples.

3.8 Specify document submittal requirements.

3.8.2 Specify type of operation and maintenance manual requirements.

4.2 Specify quality assurance document submittal requirements.

4.6.2 If required, specify endurance tests.

4.6.4 Specify leakage testing. 